\title{
SUJEITO E HISTÓRIA: A FILOSOFIA DE SARTRE ENTRE A LIBERDADE E O DETERMINISMO
}

\author{
$\underline{\text { Marcelo Vinicius Miranda Barros }}^{1}$ e Malcom Guimarães Rodrigues ${ }^{2}$ \\ 1. Bolsista PIBIC/FAPESB, Graduando em Psicologia, Universidade Estadual de Feira de Santana, e-mail: \\ marcelovmb@gmail.com \\ 2. Orientador, Departamento de Ciências Humanas e Filosofia, Universidade Estadual de Feira de Santana, e-mail: \\ $\underline{\text { malcomgr@gmail.com }}$
}

PALAVRAS-CHAVE: Marxismo existencial; Psicanálise existencial; Liberdade.

\section{INTRODUÇÃO}

A filosofia fenomenológico-existencial do filósofo francês Jean-Paul Sartre suscita questionamentos a respeito das teses em $O$ Ser e o Nada (2012) ao serem confrontadas com os pensamentos defendidos na Crítica da Razão Dialética (2002). O problema aqui presente, então, é uma clássica interrogação acerca da continuidade temática entre essas duas obras sartreanas.

Alguns anos após publicar a obra $O$ Ser e o Nada, obra na qual o ser humano aparece sempre como liberdade em situação, o filósofo existencialista Jean-Paul Sartre se dedicou também ao estudo do indivíduo como um ser inserido na sociedade, imerso na práxis, na qual a sua liberdade, ainda situada, é pensada dialeticamente com o desenvolvimento histórico (ABDO, 2013). A Crítica da Razão Dialética é a obra na qual Sartre explora a "historialização" da realidade humana, ou seja, as questões (já abertas desde $O$ Ser e o Nada) relativas à dialética entre a ação livre e individual e a determinação histórica e social (LEOPOLDO E SILVA, 2015). Assim, partindo de alguns temas de $O$ Ser e o Nada, como a Facticidade do Para-si; o $O$ Para-outro; o Ter, Fazer e Ser e, especialmente, a Psicanálise existencial, tendo por metodologia a releitura desse filósofo a respeito da "Intencionalidade", que é um conceito recriado por Husserl a partir de Brentano, para afirmar que toda consciência é consciência de alguma coisa, ou seja, a consciência, para Sartre, não é algo, não é uma substância, a consciência só existe na relação com o objeto / fenômeno, para se chegar ao "Marxismoexistencial" ou à Antropologia da Crítica da Razão Dialética, pretendemos realizar uma análise do desenvolvimento social da humanidade enquanto práxis, dialética e coletividade, a fim de investigar e compreender a aparente contradição entre sujeito/particular e história/universal.

Tal análise se justifica não só no contexto interno às obras de Sartre, em que a liberdade se torna um problema quando se trata de confrontá-la com a facticidade ${ }^{1}$ ( O Ser e o Nada) e com a história (Crítica da Razão Dialética), tendo como desdobramento o filósofo francês que se vê diante da necessidade de equacionar a práxis com a determinação histórica, como também nossa análise se justifica no contexto externo às obras sartreanas, no seu diálogo (frequentemente não tão amigável) com o marxismo. Entende-se aqui que esse marxismo, como o objeto da crítica de Sartre, não é necessariamente direcionado à Karl Marx, mas ainda

\footnotetext{
${ }^{1}$ Facticidade também é compreendido como a característica de ser um fato. É o nome que filósofos, como Heidegger e Sartre, dão àquele aspecto da existência humana que é definido pelas situações em que nos encontramos. A facticidade inclui todas aquelas minúcias fatuais acerca das quais não se tem nenhum controlo. É o caso da data do nosso nascimento, os nossos pais, ou o país em que nascemos. Ou o caso de todos termos de morrer um dia. Para Heidegger e Sartre, a facticidade é muito importante, porque constitui a base necessária de todas as nossas ações. Apenas somos livres em situação. A nossa liberdade de ação, a nossa capacidade de transcender as nossas circunstâncias, sempre foi contra um contexto de facticidade. Segundo Heidegger, é só na facticidade da sociedade, em termos de uma identidade e um sistema de valores, que nós próprios escolhemos, que exercemos a "decisão" pessoal que define a nossa existência (MAUTNER, 2010).
} 
ao neo-marxismo (SILVA, 2006), pois "nota-se que 1947 é um ano marcado pelo acirramento da crítica ao existencialismo por parte dos marxistas" (SILVA, 2006, p. 83). A crítica de Sartre ao marxismo de sua época 'tem como fundamento a chamada 'teoria do reflexo' de Lênin, segundo a qual o conhecimento é mero reflexo da realidade objetiva [...] Esta posição, obviamente, é contrária à perspectiva de Marx, que, entre outras coisas, defendia o caráter ativo da consciência, tal como se vê em suas Teses Sobre Feuerbach" (VIANA, 2008, p. 152, grifo do autor). Assim, diferente do que defendem certos marxistas, para Sartre, os indivíduos não são meros efeitos das determinações gerais: estas somente os produzem na medida em que foram produzidas por eles (LEOPOLDO E SILVA, 2015). Sartre, então, problematiza o marxismo na Crítica da Razão Dialética, e, por isso, vamos buscar o entendimento sartreano sobre as questões sociais discutidas no marxismo.

Por outro lado, a pesquisa ainda se justifica em função da continuidade de problematizações entre o $O$ Ser e o Nada e a Crítica da Razão Dialética. Não se pode dizer que na obra $O$ Ser e o Nada há somente uma análise filosófica sobre a subjetividade humana e que na obra Crítica da Razão Dialética há somente uma análise do sujeito histórico, pois "tal separação tem muito de artificial, e a leitura pautada pelo que poderia ser entendido como uma sequência de duas diferentes 'fases' do pensamento de Sartre arrisca-se a deixar escapar algo fundamental: a subjetividade, como exercício de uma liberdade radical, deve ser sempre pensada historicamente, pois a existência é, por definição, histórica" (LEOPOLDO E SILVA, 2015, p. 39).

Assim, em resumo, para Sartre, cada história subjetiva se desenrola no plano geral da história objetiva. Não há, então, a dicotomia irredutível entre a subjetividade e a objetividade ou entre o individuo e a história. Se a realidade humana é histórica também para Sartre, ela se dá por via da relação entre um sujeito, que é sempre um agente histórico, e o conjunto de condições objetivas que contextualizam a liberdade em situação: as facticidades. "Pois se é verdade que o homem está na história, também é verdade que é ele que faz a história" (LEOPOLDO E SILVA, 2015, p. 40).

Justifica-se, então, a tentativa de elaborar uma reflexão que nos seja reveladora dos mecanismos de construção da realidade social, entendida na tensão entre o sujeito e sua história, via a filosofia de Sartre. Aqui, uma das principais perguntas é: se há algum tipo de determinação da facticidade, na história, como equacioná-la com a liberdade? A questão se justifica porque Sartre parece questionar o determinismo, como aquele proveniente do marxismo mecanicista.

\section{MATERIAL E MÉTODOS OU METODOLOGIA (ou equivalente)}

Os materiais utilizados foram prioritariamente de ordem textual: livros, artigos, textos etc. A metodologia consistiu, basicamente, em encontros com o orientador, leituras, fichamentos, análises críticas e produção de textos. Os encontros com o orientador e a participação nos grupos de estudo de pesquisa foram fundamentais, especialmente no início da pesquisa, momento no qual as primeiras leituras serão discriminadas e analisadas. Depois das primeiras leituras e fichamentos, a partir de novos encontros com o orientador, passaram à produção do primeiro relatório. Com o avanço da pesquisa, foram parte da metodologia a produção de textos para eventual publicação e a participação em eventos para apresentação dos resultados parciais e/ou finais da pesquisa.

\section{RESULTADOS E/OU DISCUSSÃO (ou Análise e discussão dos resultados)}

O propósito, aqui, é analisar a noção de subjetividade na filosofia de Jean-Paul Sartre, tendo por metodologia a releitura desse filósofo a respeito da "Intencionalidade", que é um conceito recriado por Husserl a partir de Brentano, para afirmar que toda consciência é consciência de 
alguma coisa. Ou seja, a consciência, para Sartre, não é algo, não é uma substância; a consciência só existe na relação com o objeto / fenômeno (SARTRE, 2012).

Por isso, a consciência faz a análise intencional e descritiva dos objetos. Todo ato mental tem seus conteúdos, caracterizados por sua direção a um objeto. Toda crença, desejo, tem necessariamente seus objetos: o acreditado, o desejado, etc (SARTRE, 2012).

Assim se justifica porque Sartre parece questionar o determinismo, como aquele proveniente do marxismo mecanicista: exemplificando, não é necessário aqui o conceito mecanicista sobre o ser humano, uma vez que se parte do pressuposto que a consciência é intencional (toda consciência é consciência de alguma coisa) (SARTRE, 2012).

Neste sentido, a subjetividade, pelo viés de Sartre, não é imanente ao indivíduo, mas no conceito de Intencionalidade, na intersubjetividade sartreana e na relação que o sujeito tem com Outro, o olhar, que são questões discutidas em $O$ Ser e o Nada, não existindo, portanto, a separação entre o plano individual e o coletivo, entre os registros de indivíduo e sociedade, eliminando, segundo Sartre, o modelo cartesiano de dualidade: sujeito e objeto (SARTRE, 2012).

Antes de prosseguirmos com este texto é necessário fazer, aqui, uma delimitação dos conceitos o Ser-em-si (Em-si) e o Ser-para-si (Para-si), já que estes são condições fundamentais para discorrer sobre a consciência na filosofia sartreana. O Em-si existe aí no mundo, independente de qualquer coisa, e diz respeito às coisas tal como se apresentam para nós, como sendo fenômeno ou aparição. O Para-si é a consciência humana que ao se defrontar com o mundo torna-se um processo dinâmico (contrastando com a inércia do Em-si) e faz com que o Em-si se desvele ou se apresente como fenômeno da consciência. Assim, o Em-si, nesse sentido, seria o objeto que aparece à consciência como fenômeno. Mas, não se pode aceitar que a consciência seja abstrata, por parecer esconder uma origem ontológica no Em-si, e, reciprocamente, que o fenômeno seja igualmente abstrato, já que precisaria "aparecer" à consciência, pois, de fato, a totalidade sintética consciência-fenômeno ou Intencionalidade é que é o concreto. Dessa forma, Sartre evita a dualidade: sujeito e objeto / subjetividade e objetividade (SARTRE, 2012).

Porém, o entendimento desses dois tipos de seres (o Para-si e o Em-si) não resultou no estabelecimento de um hiato a cindir o Ser? Não, pois o Para-si e o Em-si estão reunidos em uma conexa sintética que nada mais é do que o próprio Para-si. Com efeito, o Para-si não constitui senão a pura nadificação do Em-si. Portanto, não cabe interrogar a respeito da maneira como o Para-si pode se unir ao Em-si, já que o Para-si não é, de forma alguma, uma substância autônoma. Com outras palavras, o ser-Em-si e o ser-Para-si não simbolizam uma dualidade do tipo Corpo-Alma, é uma característica inerente a existência humana. Sendo Intencionalidade, ao mesmo tempo, o sujeito sartreano é objetividade e subjetividade, não podendo ser reduzido a nenhuma destas duas dimensões (SARTRE, 2012).

Não que o Em-si não exista sem a consciência, senão estaríamos caindo no Idealismo, que Sartre tanto combateu. Isto significa que o objeto só tem sentido para a consciência. Sem essa intencionalidade não haveria possibilidade de falar sobre o objeto. Dessa forma, o fenômeno é o objeto da consciência, para que ela possa existir e vice-versa. Consciência e fenômeno existem contemporaneamente. Se a consciência existisse antes do fenômeno, estaríamos no Idealismo; já se o fenômeno existisse antes da consciência, estaríamos no Realismo (SARTRE, 2012).

Isso significa afastar dos extremos tanto do realismo quanto do idealismo - afinal, conforme o próprio escrito de Sartre, idealismo e realismo dissipam de modo semelhante o real, um porque suprime a coisa, o outro porque suprime a subjetividade. $\mathrm{O}$ filósofo francês, então, 
procura vencer essa polaridade, partindo, dentre outros conceitos, o da intencionalidade da consciência (SARTRE, 2012).

\section{CONSIDERAÇÕES FINAIS (ou Conclusão)}

Sartre é um filósofo polêmico, não só pelo seu conceito de liberdade que é recriminado por diversos pensadores, especialmente por certos marxistas, como também por suscitar questionamentos a respeito de suas obras; por exemplo, quando as teses de $O$ Ser e o Nada são confrontadas com as posições defendidas na Crítica da Razão Dialética, há, então, um problema clássico que se apresenta ao se interrogar a respeito da continuidade temática em ambas as obras.

Entendemos que o humanismo, como compreendido pelo existencialismo sartreano, permaneceria constante, apesar da contradição que pode ser estabelecida entre a fenomenologia e o marxismo por parte de certos críticos. Contrariando as ditas "fases diferentes", compreendemos também que há uma continuidade temática, descrevendo em ambas as obras o fenômeno humano em seu lado individual e coletivo, ou seja, a liberdade permanece em todo sistema filosófico de Sartre sem negar a história.

Há a "dialética" sartreana ou reciprocidade do objetivo e do subjetivo, já que o sujeito existe como subjetividade objetivada, que pela subjetividade (consciência), se objetiva novamente, encontrando, por meio da subjetividade, uma nova objetivação e assim infinitamente. Salientando que esse processo intencional da consciência com o objeto é contemporâneo, logo a subjetividade e a objetividade também os são. Portanto, já não se supõe que haja um sujeito e um mundo preestabelecidos. Ao contrário, o mundo e o sujeito são contemporâneos (SARTRE, 2002). Essa "dialética" ou reciprocidade evita, então, para Sartre, o fundamento chamado "teoria do reflexo" de Lênin, que era ideologicamente marxista, segundo a qual o conhecimento é mero reflexo da realidade objetiva (SILVA, 2006).

O que tentamos esclarecer é que a subjetividade se constrói na relação entre o mundo já dado (a história) e a existência humana (o sujeito). Na verdade, ao se tratar de uma relação dialética entre o "externo" (história) e o "interno" (sujeito), o subjetivo é ao mesmo tempo processo e resultado, em constante construção. Não existe, então, dualidade externo e interno. Ou seja, o mundo interno não é necessariamente representação do externo, nem vice-versa, pois são planos que se transversalizam simultaneamente. Como entendido, Sartre se afasta do pensamento cartesiano: interno e externo ou subjetivo e objetivo (SARTRE, 2002).

\section{REFERÊNCIAS}

ABDO, R, N. Sobre a Crítica da razão dialética de Sartre. Revista Cognitio-Estudos. P. 001011, Vol. 10, nº. 1, janeiro-junho, 2013.

LEOPOLDO E SILVA, F. Sartre e a psicanálise: subjetividade e história. Cienc. Cult. vol.67 n.1 São Paulo Jan./Mar. 2015.

MAUTNER, T. Dicionário de Filosofia. São Paulo: Editora Edição 70, 2010.

SARTRE, J-P. O Ser e O Nada: Ensaio De Ontologia Fenomenológica. $21^{\text {a }}$ Edição. Petrópolis: Editora Vozes, 2012.

. Crítica da Razão Dialética. Tomo 1. Rio de Janeiro: DP\&A Editora, 2002.

SILVA, D, L. Existencialismo e marxismo: a filosofia de Sartre entre a liberdade e a história. [Tese]. Programa de Pós-graduação em Filosofia. Universidade Federal de São Carlos UFScar. São Carlos, 2006.

VIANA, N. Sartre e o marxismo. Filosofia Unisinos, 9(2):146-161, 2008. 